\title{
Imaging Spectrum of Renal Replacement Lipomatosis: A Case Series
}

\section{Reddy Ravikanth 1, ParthaSarathi Sarkar 2*, Arun George 33, Babu Philip 4.}

${ }^{1}$ Post-graduate student in Radiology, St. John's M edical College, Bangalore, Karnatka, India.

*2 Senior Resident in Radiology, St. John's M edical College, Bangalore, Karnatka, India.

${ }^{3}$ Associate Professor in Radiology, St. John's M edical College, Bangalore, Karnatka, India.

${ }^{4}$ Professor in Radiology, St. John's M edical College, Bangalore, Karnatka, India.

\section{ABSTRACT}

Renal replacement lipomatosis is a rare benign entity, characterized by diffuse replacement of renal parenchyma, sinus and hilum with adipose tissue resulting in renal parenchymal atrophy. Etiology may be secondary to obesity, cushing's syndrome, corticosteroid excess or idiopathic. Renal replacement lipomatosis is usually secondary to renal calculus and renal tuberculosis, occasionally occurs after renal infarction and is frequently associated with xanthogranulomatous pyelonephritis. CT provides a definitive diagnosis of renal replacement lipomatosis and is considered superior to ultrasonography, which is not very sensitive for detecting fatty proliferation. CT is considered to be best to differentiate renal replacement lipomatosis from other fat rich lesions, such as renal angiomyolipoma, retroperitoneal lipoma and liposarcoma.

KEY WORDS: Imaging, Lipomatosis, Renal, Sinus, Hydronephrosis.

Address for correspondence: Dr. ParthaSarathiSarkar, MBBS, DM RD, DNB, Senior Resident in Radiology, St. John's M edical College, Bangalore - 560034, Karnataka, India. M ob: +91-8861522272 E-M ail: drparthasarathisarkar@gmail.com

\begin{tabular}{|c|c|c|}
\hline \multicolumn{3}{|c|}{ Online Access and Article Informtaion } \\
\hline \multirow{2}{*}{$\begin{array}{c}\text { Quick Response code } \\
\text { Dol: } 10.16965 / \text { ijims.2016.126 }\end{array}$} & \multicolumn{2}{|c|}{$\begin{array}{l}\text { International Journal of Integrative Medical Sciences } \\
\text { www.imedsciences.com }\end{array}$} \\
\hline & $\begin{array}{l}\text { Received: 06-06-2016 } \\
\text { Reviewed: 06-06-2016 }\end{array}$ & $\begin{array}{l}\text { Accepted: 14-06-2016 } \\
\text { Published: 30-06-2016 }\end{array}$ \\
\hline Source of Funding: Self & \multicolumn{2}{|c|}{ Conflicts of interest: None } \\
\hline
\end{tabular}

\section{BACKGROUND}

Renal replacement lipomatosis represents an abnormal proliferation of the adipose tissue surrounding the renal pelvis of uncertain origin, associated with aging, obesity, steroid excess, infections and calculosis. It is associated with processes causing atrophy of renal tissue. When long standing inflammation exists in a kidney, replacement lipomatosis may be the end result. The renal cortex is atrophied, with varying degrees of hydronephrosis or pyonephrosis and calculi [1]. CT accurately demonstrates the distinctive features of renal replacement lipomatosis which are abundant fatty tissue, characteristic distribution of fat within renal sinus and perinephric space with calculi and atrophied renal parenchyma.

CASE 1: A 66 year old elderly lady was admitted with complaints of right flank pain. She underwent open cholecystectomy and hysterectomy. Investigations revealed urinary tract infection with E.coli and Klebsiella sp. Creatinine clearance was $80 \mathrm{ml} / \mathrm{min}$ and hemogram was unremarkable. CT showed an enlarged right kidney with hydronephrosis, parenchymal atrophy with marked fatty proliferation within the right renal sinus. 
Fig. 1: Axial CTimage showing enlarged right kidney with hydronephrosis and fatty proliferation of the renal sinussuggesting renal replacement lipomatosis.

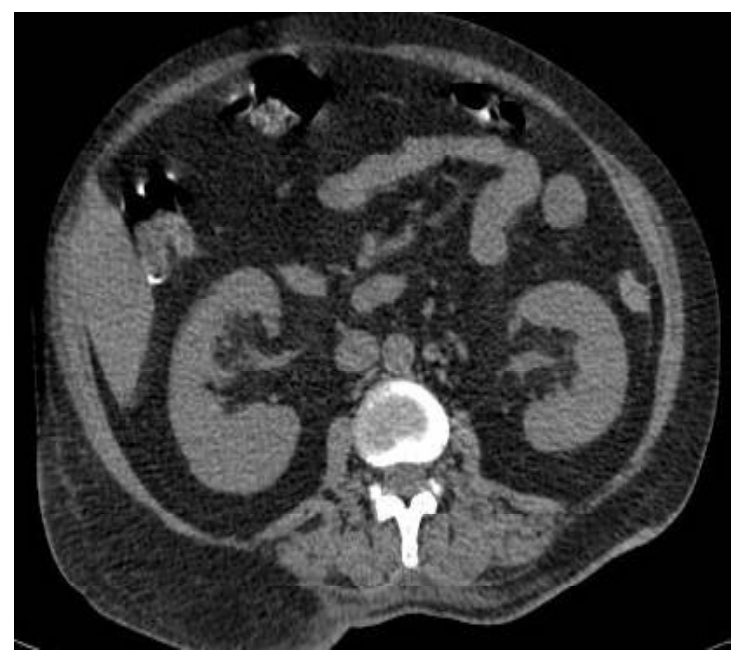

CASE 2: A 55 year old elderly lady was admitted with complaints of right flank pain. She had history of weight loss of $20 \mathrm{~kg}$ in the last 8 months. Open surgical drainage for a right flank abscess was done 4 months earlier. Investigation revealed urinary tract infection with E.coli. CT showed enlarged right kidney with hydronephrosis with marked fatty sinus proliferation.

Fig. 2: Axial CT image demonstrating abnormal proliferation of the adipose tissue surrounding the renal pelvis with fatty proliferation of the renal sinus causing hydronephrosis of the right kidney.

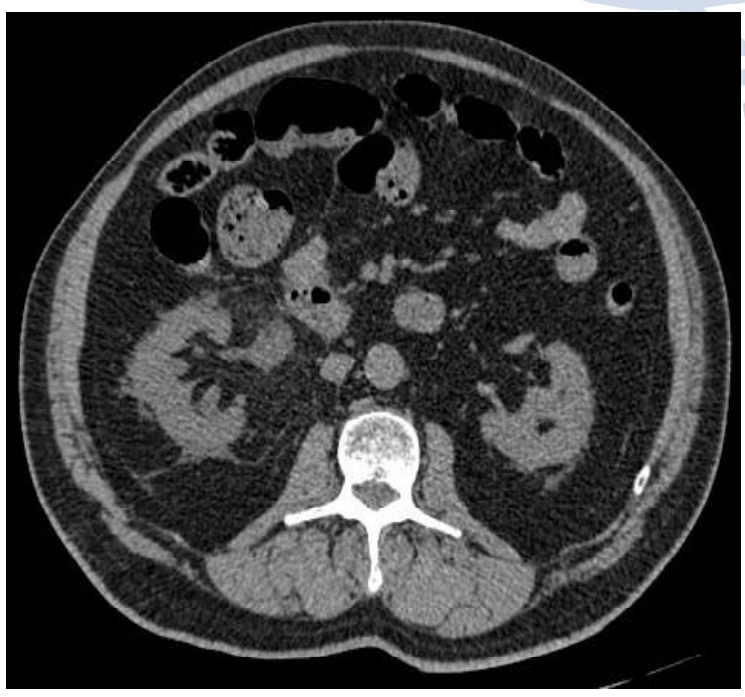

CASE 3: A 30 year old pregnant woman presented in her 12th week of pregnancy with history of episodic bilateral flank pain and fever for past 2 years. Urine analysis revealed numerous pus cells. Culture of urine grew Staphylococcus aureus. Abdominal CT was not performed considering the pregnancy status. Magnetic resonance imaging revealed atrophy of bilateral kidneys, which are almost completely replaced by fat. Marked proliferation of the fatty tissue was also seen in the perinephric space.

CASE 4: A 62 year old gentleman presented with bilateral flank pain for 6 months, and hematuria for last 2 years. Physical examination was unremarkable. Urine analysis showed 30-35 red blood cells/hpf and 20-25 pus cells/ hpf. CT revealed bilateral contracted kidneys with proliferation of the perinephric fat compressing the renal parenchyma, suggesting renal replacement lipomatosis.

Fig. 3 and 4: Axial and coronal MRI images showing bilateral shrunken kidneys with sinus fat proliferation suggesting chronic kidney disease with renal replacement lipomatosis.

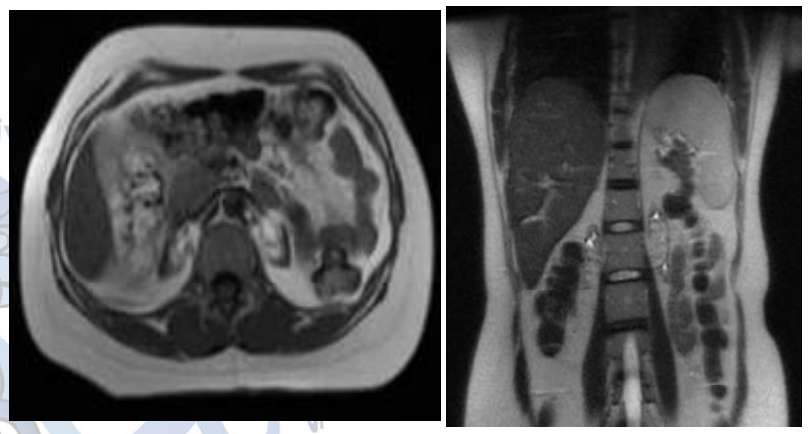

Fig. 5: Axial CT image demonstrating bilateral contracted kidneys with abnormal proliferation of the perinephric fat causing compression of the renal parenchyma in a case of renal replacement lipomatosis.

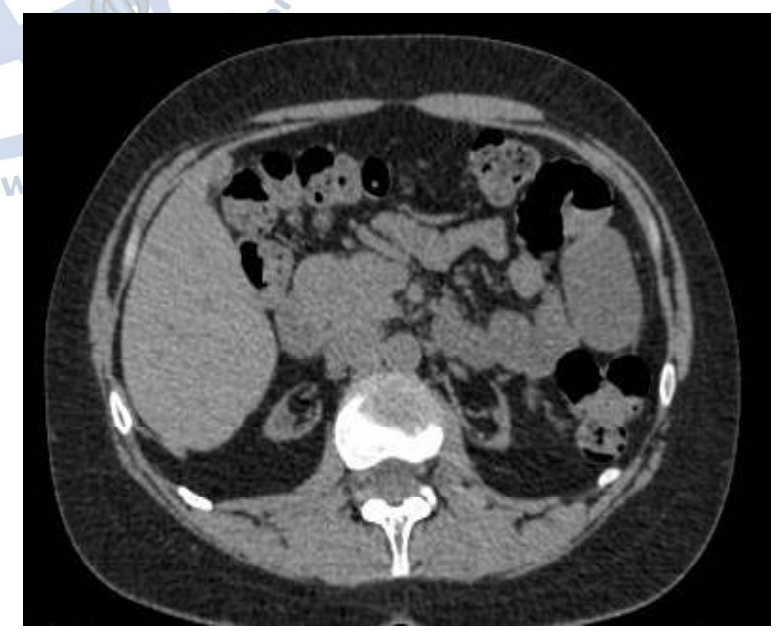

DISCUSSION

Renal lipomatosis may mimic and may be confused with a neoplasm of the kidney. Some differential diagnoses include liposarcoma, lipoma, angiomyolipoma and transitional cell carcinoma of the renal sinus. In contrast to renal replacement lipomatosis, these tumors are usually located intrarenally or extrarenally outside the renal sinus [2]. 
Renal replacement lipomatosis may be due to chronic inflammation, $70 \%$ of which are associated with a calculus. Renal calculi have been found to cause obstruction of the renal collecting system, which subsequently results in hydronephrosis, chronic infection and eventual atrophy of the renal parenchyma. This is often followed by replacement of the destroyed renal parenchyma by fatty tissue [3]. The development of renal lipomatosis has also been attributed to long-term steroid administration, chronic leakage of urine in the perinephric tissue, renal tuberculosis and renal infarction. Other possible risk factors include aging, obesity, atherosclerosis and chronic urinary tract infection.

The radiological features of replacement lipomatosis may vary. Renal calculi are often present, and sometimes increased lucency in the area of the kidney due to increased amounts of fat may be recognized. This lucency replacing the normal water density of the kidney is the only specific radiographic change in replacement lipomatosis [4]. In some cases, fat may not be radiographically apparent, especially if a large amount of fibrous tissue is associated with it causing mass effect. The radiologic finding of a lucent mass surrounding a staghorn calculus with a non-functioning kidney is pathognomonic of renal replacement lipomatosis [5].

Ultrasound often shows a hypoechoic rim of residual renal parenchyma with a hyperechoic mass at the center, representing the lipomatous mass. CT demonstrates the destroyed renal parenchyma and the lipomatous mass with a negative attenuation similar to normal adipose tissue. CT features of frenal replacement lipomatosis clearly distinguish this entity from hydronephrosis, cysts and non-fatty containing tumors based upon attenuation values [6]. Theoretically the attenuation of lipomatous tissue may approach zero simulating a hydronephrosis, cyst or myxoidliposarcoma if the fat/fibrous tissue ratio decreases. Fat containing neoplasms arising in the renal parenchyma, renal sinus, renal capsule or perinephric space such as angiomyolipoma, lipoma and liposarcoma should also be readily be differentiated from renal replacement lipomatosis. M R images may demonstrate renal cortical cysts, atrophy of kidneys, extensive perirenal soft tissue, and diffuse homogenous suppression of perirenal fat tissue [7].

\section{CONCLUSION}

Renal replacement lipomatosis is the result of severe atrophy or destruction of the renal parenchyma often caused by calculous disease with secondary marked proliferation of renal sinus, renal hilum and perirenal fatty tissue. Renal lipomatosis is a rare condition that should be differentiated from other neoplasms of the kidney. CT is an accurate method in diagnosing renal replacement lipomatosis obviating the need for diagnostic surgery in typical cases. When sugery is indicated for therapeutic reasons $C T$ can often be of value in the preoperative planning to demonstrate the degree of fibrous fatty proliferation in relation to adjacent organs.

\section{REFERENCES}

[1]. Badar F, Azfar SF, Wahab S. Kidney Diseases Renal Replacement Lipomatosis With Coexisting Xanthogranulomatous Pyelonephritis in a Pregnant Woman. 2011;5(4):275-7.

[2]. Choh NA, Choh SA. Renal replacement lipomatosis: A rare type of renal pseudotumor. 2016;20(2):923.

[3]. Khan M, Nazir SS, Ahangar S, Javid S, Qadri F, Salroo NA. Total renal replacement lipomatosis. Int J Surg [Internet]. Elsevier Ltd; 2010;8(4):263-5. Available from: $h$ ttp://dx.doi.org/10.1016/j.ijsu.2010.02.009

[4]. Kullendorff B, Nyman U, Aspelin P. Computed Tomography in Renal Replacement Lipomatosis. 2016;1851(June).

[5]. Posadas M A, Chua E, Thomas B, Savage SJ, Baliga P. Allograft dysfunction in a patient with an oddlooking kidney/ : case of renal lipomatosis and review of literature. 2012;359-61.

[6]. Ratkal V, Chawla A, Mishra DK, Krishna S. Renal replacement lipomatosis of the right kidney. 2015;2:2014-6.

[7]. Mutlu H. REPLACEM ENTLIPOM ATOSISOF THE KIDNEY: M RI FEATURES. 2008;0-2.

How to cite this article: Reddy Ravikanth, ParthaSarathi Sarkar, Arun George, Babu Philip. Imaging Spectrum of Renal Replacement Lipomatosis: A Case Series. Int Intg Med Sci 2016;3(6):309-311. DOI: 10.16965/ijims.2016.126 